\title{
Three Cases of the Giant Gastric Leiomyosarcomas
}

\author{
NAOFUMI ERIGUCHI, SHIGEAKI AOYAGI, MASAO HARA AND HISANORI NAITO*
}

Department of Surgery, Kurume University School of Medicine, Kurume 830-0011 and *Naito Hospital, Kurume 830-0038, Japan

\begin{abstract}
Summary: We report three cases of giant gastric leiomyosarcoma. Diagnosis was made prior to surgery using various diagnostic modalities. The patients were two women (77 and 77 years old) and one man (40 years old) whose chief complaints were abdominal pain, anorexia, and tarry stool. All patients presented with a large palpable mass in their upper abdomen at the time of admission. Based on characteristic findings from a gastric barium study, computed tomography (CT), and angiography, the patients were diagnosed as having gastric leiomyosarcomas displaying extramural growth. In the first case, a patient received a total gastrectomy, while local resection was performed in the second case because of pedunculated extragastric development. In the third case, total gastrectomy was combined with splenectomy and resection of the pancreatic tail. Twenty-two months after the original operation, the first case had multiple liver metastases. We present the three cases here, and review the literature.
\end{abstract}

Key words leiomyosarcoma, extramural growth, gastric submucosal tumor

\section{INTRODUCTION}

Gastric leiomyosarcoma is reported to account for $0.1-2 \%$ of all gastric malignancies [1,2]. Giant gastric leiomyosarcomas with a major diameter of over $15 \mathrm{~cm}$ are rare. The symptoms or signs such as palpable abdominal mass and abdominal pain are not necessarily specific to leiomyosarcoma. Approximately 60 cases have been collected from the literature and studied. To these we add three cases from our institution.

\section{CASE REPORT}

\section{Case 1}

A 40-year-old man was admitted to our hospital with complaint of a tarry stool, hematemesis and vomiting. He noted no weight loss. A mass was located in the upper left abdomen and could be palpated. Leiomyosarcoma of the stomach was diagnosed by upper gastrointestinal series, abdominal ultrasonography (US), and selective celiac angiography (Fig.1). Total gastrectomy with lymph node dissection was performed. Tumor size was $18 \times$
$17 \times 16 \mathrm{~cm}$. The resected specimen showed a leiomyosarcoma with high cellularity and many mitoses. Twenty-two months after the original operation, the abdominal computed tomography showed multiple liver metastatic lesions. He died 5 months after discovery of the liver metastasis due to metastatic disease.

\section{Case 2}

A 77-year-old woman was admitted to our hospital with complaints anorexia and a palpable mass in the upper abdomen. She was diagnosed as having a submucosal tumor of the stomach by an upper gastrointestinal series and abdominal computed tompgraphy (CT) (Fig. 2). Laparotomy was performed and the tumor was pedunculated from the great curvature of the stomach wall and was excised by wedge resection. The pathological diagnosis of the excised tumor was extragastric leiomyosarcoma. Post operative course was uneventful. The tumor size was $18 \times 16 \times 12 \mathrm{~cm}$ with a partly cystic lesion. The tumor arose on the gastric wall with no adhesion or invasion to the adjacent organs. 


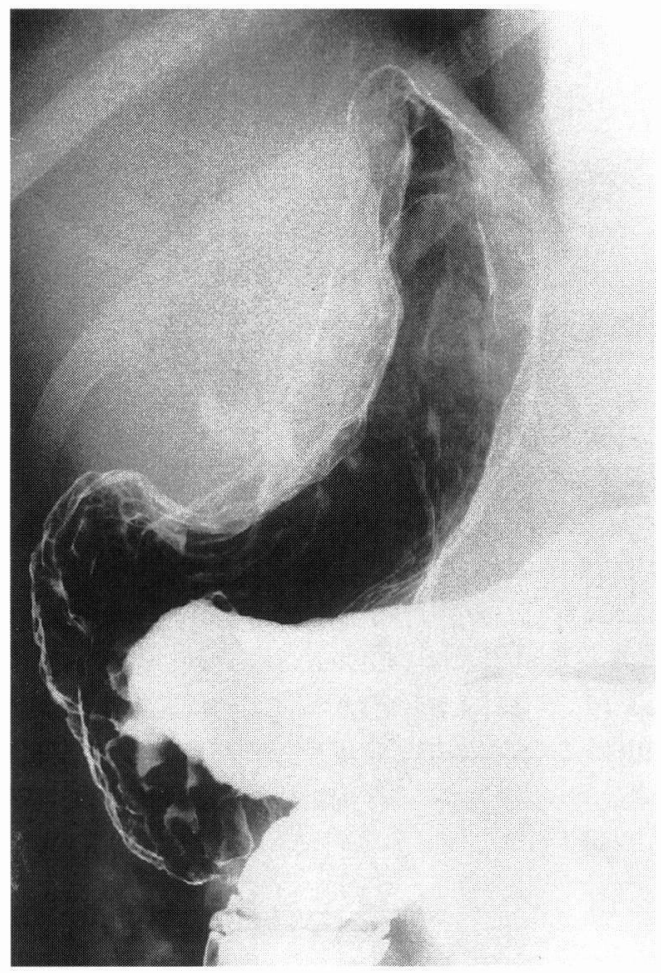

(a)

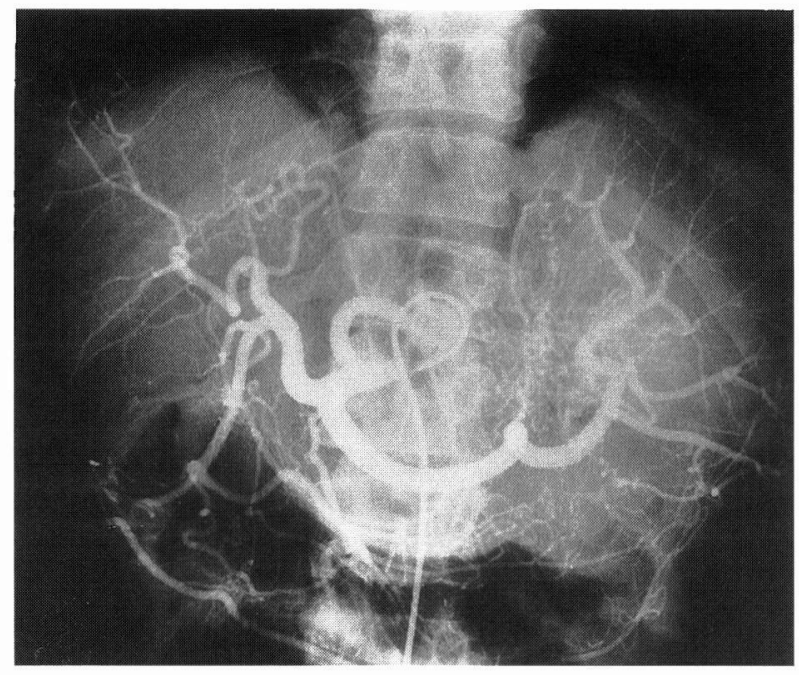

(b)

Fig. 1. a) Barium examination of the stomach shows a massive tumor occupying the greater curvature of the Fornix. b) Celiac angiogram demonstrated hypervascular tumors, which were fed by the left and splenic arteries.

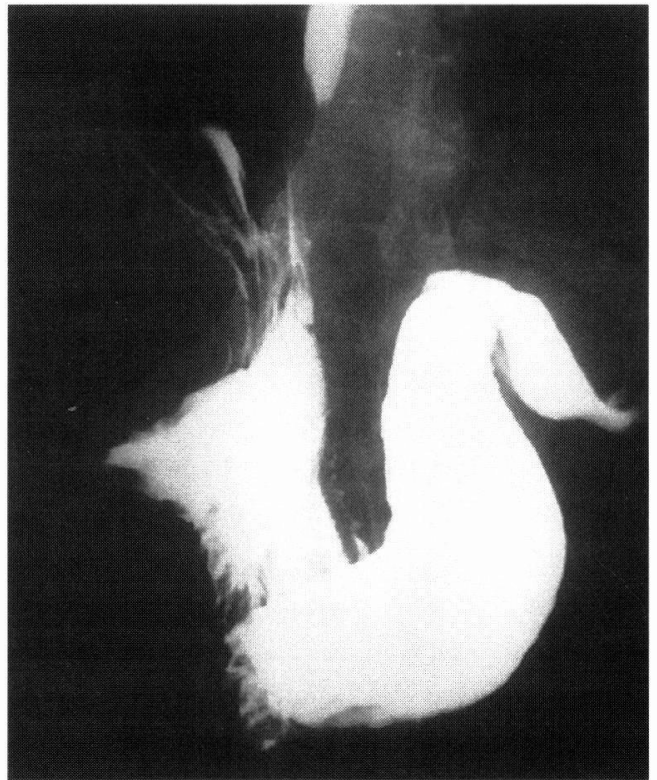

(a)

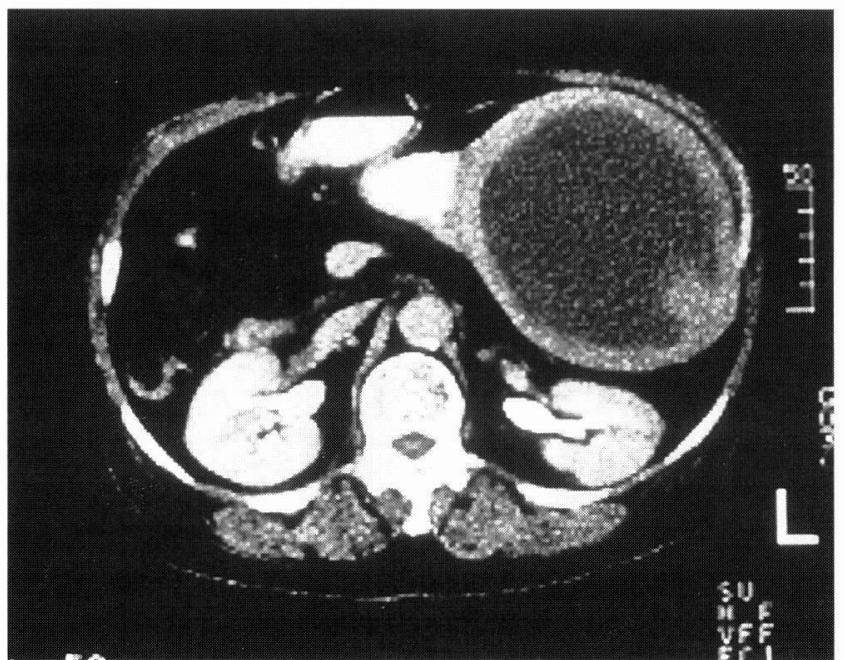

(b)

Fig. 2. a) Barium examination of the stomach shows a massive tumor occupying the fornix of the stomach. b) Abdominal CT scan with contrast enhancement. A huge low density mass can be observed in the abdominal cavity. The tumor margin is markedly enhanced. 

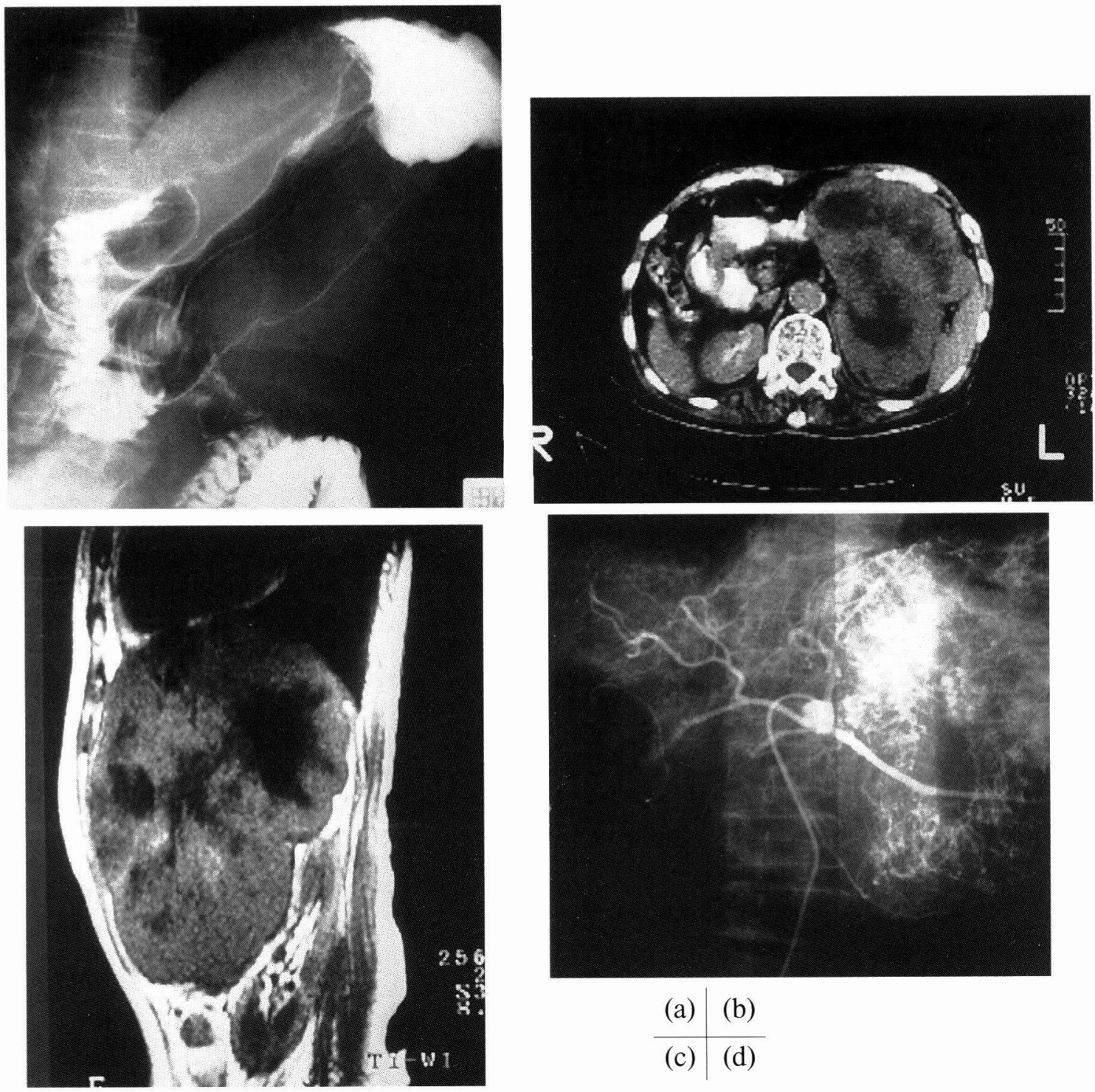

\begin{tabular}{l|l} 
(a) & (b) \\
\hline (c) & (d)
\end{tabular}

Fig. 3. a) Barium examination of the stomach shows a massive tumor occupying the greater curvature of the gastric body. b) Abdominal CT scan. A huge low density mass can be observed in the abdominal cavity. c) Abdominal MRI. The T1-WI sagital section shows a large, well defined, low intensity mass with central necrosis. d) Celiac angiogram. Arterial phase reveals neovascularization of both the left gastric and splenic arteries.

\section{Case 3}

A 77-year-old woman was admitted to our hospital with complaints of abdominal pain and a palpable mass in the upper abdomen. She was diagnosed as having a leiomyosarcoma of the stomach by the abdominal CT, celiac angiography, magnetic resonance imaging (MRI) and abdominal US (Fig. 3).

Total gastrectomy with resection of the pancreatic tail and spleen was performed because of invasion to the adjacent organs. Postoperative histological findings showed a leiomyosarcoma with high cellularity but with no invasion of the pancreas or spleen.

The most common symptoms in our series were palpable mass, the size varying from $17 \times 16 \times 16 \mathrm{~cm}$ to $18 \times 17 \times 16 \mathrm{~cm}$. Two patients received total gastrectomy and local resection was performed in one patient. Abdominal angiography revealed hypervascular findings and abdominal CT revealed a low density mass in all patients (Table 1). 
TABLE 1.

Leiomyosarcoma of the stomach in our cases

\begin{tabular}{|c|c|c|c|c|c|c|c|c|}
\hline No & Age & Sex & Major complaint & GI series & Angiography & $\mathrm{CT}$ & Procedure & Outcome \\
\hline 1 & 40 & $\mathrm{M}$ & $\begin{array}{l}\text { tarry stool } \\
\text { palpable mass }\end{array}$ & defect of the fornix & hypervascular & $\begin{array}{l}\text { mass lesion } \\
18 \times 17 \times 16 \mathrm{~cm}\end{array}$ & total resection & $\begin{array}{l}\text { liver meta, no } \\
22 \mathrm{mo} \text {. later }\end{array}$ \\
\hline 2 & 77 & $\mathrm{~F}$ & $\begin{array}{l}\text { anorexia } \\
\text { palpable mass }\end{array}$ & compression finding & hypervascular & $\begin{array}{l}\text { mass lesion } \\
18 \times 16 \times 12 \mathrm{~cm}\end{array}$ & local resection & \\
\hline 3 & 77 & $\mathrm{~F}$ & $\begin{array}{l}\text { abdominal pain } \\
\text { palpable mass }\end{array}$ & compression finding & hypervascular & $\begin{array}{l}\text { mass lesion } \\
17 \times 16 \times 16 \mathrm{~cm}\end{array}$ & total resection & \\
\hline
\end{tabular}

GI series: gastro-intestinal series mo.: month no: negative lymph node metastasis

\section{DISCUSSION}

Gastric leiomyosarcomas are rare tumors. Leiomyosarcoma is reported to account for $20-43 \%$ of all gastric sarcoma. Its incidence is second only to malignant lymphoma [2]. The most common symptoms and signs of large tumors were abdominal pain, palpable mass and abdominal distension. None of these symptoms is specific to leiomyosarcoma. The disease most frequently occurs in the upper third of the gastric body, followed by the middle third and then the lower third $[1,4]$. According to the classification system of Skandalakis [4], leiomyosarcoma can be divided into four types; exogastric, endogastric, intramural, and exogastric +endogastric. In about half of all cases, the disease displays exogastric growth $[1,2,5]$. Only approximately 60 cases with a tumor diameter over $15 \mathrm{~cm}$ have been reported in Japan. Since 1989, there have been 24 cases of over $10 \mathrm{~cm}$ in size reported in the Japanese literature (Table 2) [6-21]. The average age in these cases was 57.2 years, with a ratio of 16 men to 8 women. The principal symptoms in these cases were palpable mass and abdominal pain. A definite preoperative diagnosis of leiomyosarcoma is often difficult to obtain using diagnostic imaging methods. For diagnosis of the disease, roentgenography, US, CT and angiography were effectively used, and angiography in particular enabled clarification of the vascularization of the tumors, by which it was often possible to determine the organ in which the tumors initially developed. There is universal acceptance in the literature that the treatment of choice is surgical excision. The most common type of resection was wide local excision, performed in 14 patients. Distal subtotal gastrectomy (2 patients), total gastrectomy (4 patients), and fundectomy (1 patient) constituted the other types of surgical treatment. The extent of surgical therapy required to achieve satisfactory long-term results is subject to debate. Most consider removal of the tumor together with a margin, by resection of the gastric wall or partial gastrectomy, as sufficient treatment. The tumor invades the adjacent structures directly and metastasizes via the blood stream, especially to the liver and lungs, but it rarely spreads to the regional lymph nodes [22] or to the omentum. Although metastasis to the lymph nodes was found in other published cases [23], Kurita et al. [21] reported that there were no lymph nodes metastases in cases where the tumor was less than 9 $\mathrm{cm}$ in diameter. Therefore, radical surgery, as employed in carcinoma of the stomach, is not indicated unless metastases are observed intraoperatively. According to Crocker's [24] and Roles's [25] study the margin should be at least $2 \mathrm{~cm}$. Local resection with an adequate margin is sufficient. Radiotherapy is of little practical use, as these tumors are radio resistant [25]. Chemotherapy also has been used infrequently with little benefit [20]. However, the combination of chemotherapy with radiotherapy, or reoperation, is still recommended for lack of viable alternatives. Miya et al. [20] reported a case of multiple liver metastasis 18 months after a total gastrectomy for giant leiomyosarcoma of the stomach had been performed. Transarterial hepatic chemo-embolization therapy was one of the most effective treatments for liver metastases. Prognosis in these tumors is dependent on histopathological grade, tumor size, and evidence of invasion of adjacent organs. Five year survival for patients with tumors of low grade malignancy is $81 \%$ versus $32 \%$ for high grade tumors [26]. The median interval to recurrence is 24 months.

In summary, we recommend tumor resection with a margin of the gastric wall or partial gastrectomy, if there are no invasive findings to adjacent organs or lymphnodes metastases. 
TABLE 2.

Reported cases of giant leiomyosarcoma of the stomach in Japan (from 1989)

\begin{tabular}{|c|c|c|c|c|c|c|c|c|}
\hline No & Author & & Age & Sex & Major complaint & Procedure & Size of tumor & Outcome \\
\hline 1 & Ashida & '89 & 69 & $\mathrm{~F}$ & abdominal discomfort & wedge resection & $16.0 \mathrm{~cm}$ & \\
\hline 2 & Tajima & '89[7] & 39 & M & palpable mass & wedge resection & $18.0 \mathrm{~cm}$ & $15 \mathrm{mo}, \mathrm{A}$ \\
\hline 3 & Kitamura & $90^{[8]}$ & 64 & $\mathrm{~F}$ & palpable mass & wedge resection & $12.0 \mathrm{~cm}$ & $6 \mathrm{Y}$, rec. \\
\hline 4 & Murakami & '91 ${ }^{[9]}$ & 65 & M & abdominal fullness & wedge resection & $15.0 \mathrm{~cm}$ & \\
\hline 5 & Shirai & ' $91^{[10]}$ & 68 & $\mathrm{~F}$ & abdominal distension & subtotal gastrectomy & $20.0 \mathrm{~cm}$ & \\
\hline 6 & Kobayashi & $92^{[11]}$ & 77 & M & back pain & & $10.0 \mathrm{~cm}$ & $\mathrm{P}(+)$ \\
\hline 7 & Kishimoto & $92^{[12]}$ & 48 & M & none & fundectomy. & $10.0 \mathrm{~cm}$ & \\
\hline 8 & Iyoda & $93^{[13]}$ & 52 & $\mathrm{~F}$ & palpable mass & wedge resection & $22.0 \mathrm{~cm}$ & $10 \mathrm{mo}, \mathrm{A}$ \\
\hline 9 & Sasaki & '93 $3^{[14]}$ & 58 & $\mathrm{~F}$ & nausea & wedge resection & $18.0 \mathrm{~cm}$ & $1.5 \mathrm{Y}, \mathrm{A}$ \\
\hline 10 & Tachibana & '94[15] & 70 & M & palpable mass & distal gastrectomy & $19.0 \mathrm{~cm}$ & \\
\hline 11 & Tsurui & '94[16] & 40 & M & abdominal fullness & subtotal gastrectomy & $45.0 \mathrm{~cm}$ & $1.2 \mathrm{Y}, \mathrm{A}$ \\
\hline 12 & Kato & '95 $5^{[17]}$ & 69 & M & abdominal mass & wedge resection & $12.0 \mathrm{~cm}$ & \\
\hline 13 & Tatsuzawa & ${ }^{\prime} 95^{[18]}$ & 57 & M & abdominal pain & partial + DP + splenectomy & $20.0 \mathrm{~cm}$ & \\
\hline \multirow[t]{5}{*}{14} & Inoue & $' 95^{[19]}$ & 83 & M & palpable mass & partial resection & $20.0 \mathrm{~cm}$ & \\
\hline & & & 49 & $\mathrm{~F}$ & epigastralgia & tumor resection & $10.0 \mathrm{~cm}$ & \\
\hline & & & 51 & M & abdominal pain & tumor resection & $20.0 \mathrm{~cm}$ & \\
\hline & & & 61 & $\mathrm{~F}$ & palpable mass & tumor resection & $30.0 \mathrm{~cm}$ & \\
\hline & & & 35 & M & palpable mass & tumor resection & $13.0 \mathrm{~cm}$ & \\
\hline 15 & Ito & $' 96^{[2]}$ & 60 & M & none & wedge resection & $14.5 \mathrm{~cm}$ & \\
\hline 16 & Miya & '97[20] & 56 & M & palpable mass & total resection & $19.0 \mathrm{~cm}$ & $1.6 \mathrm{Y}, \mathrm{A}$ \\
\hline \multirow[t]{4}{*}{17} & Kurita & $' 97^{[21]}$ & 74 & M & & total resection & $22.0 \mathrm{~cm}$ & $8 \mathrm{mo}, \mathrm{D}, \mathrm{H}(+), \mathrm{P}(+)$ \\
\hline & & & 48 & M & & total resection & $13.0 \mathrm{~cm}$ & $11 \mathrm{mo}, \mathrm{D}, \mathrm{P}(+)$ \\
\hline & & & 59 & M & & wedge resection & $20.0 \mathrm{~cm}$ & $24 \mathrm{mo}, \mathrm{D}, \mathrm{P}(+)$ \\
\hline & & & 64 & $\mathrm{~F}$ & & total resection & $12.0 \mathrm{~cm}$ & $13 \mathrm{mo}, \mathrm{D}, \mathrm{H}(+)$ \\
\hline
\end{tabular}

DP: distal pancreatectomy; rec.: recurrence of tumor; $\mathrm{H}(+)$ : liver metastasis; mo: month; $\mathrm{Y}$ : year

$\mathrm{P}(+)$ : peritoneal dissemination; A: alive; D: died

\section{REFERENCES}

1. Oi M, Miho O, Ito $\mathrm{T}$, Hara $\mathrm{H}$, Takahashi $\mathrm{N}$ et al. Noncancerous tumors of stomach. Geka (Surgery) 1967; 29:112-133. (in Japanese)

2. Ito Y, Takagi K, Tomita T, Sakuma A, Itoh S et al. A case report of gastric leiomyosarcoma showing pedunculated extragastric development. Prog Dig Endosc 1996; 49:198-199. (in Japanese)

3. Shiu MH, Farr GH, Papachristou DN, and Hajdu SI. Myosarcoma of the stomach. Natural history, prognostic factors and management. Cancer 1982; 49:177-187.

4. Skandalakis JE, Gray SW, and Shepard D. Smooth muscle tumors of the stomach. International Abstracts of Surgery $1960 ; 110: 209-226$.

5. Uchida Y, Tomonari K, Fujishima N, Yasunaga A, Murakami S et al. Huge leiomyosarcoma of the stomach. J Jpn Soc Clin Surg 1986; 47:1063-1067. (in Japanese)

6. Ashida C, Nosaka J, Miyaji T, Taninaka K, Ogawa T et al. A case of leiomyosarcoma of the stomach growing extragastric space after 1 year and 4 months at the initial admission. Gann no Rinsho (Jpn J Cancer Clin) 1989; 35:505-511. (in Japanese)

7. Tajima K, Kuge Y, Shimada Y, Tsuzuki H, Hayashi K et al. Giant extra-gastric leiomyosarcoma of the stomach with intra-abdominal hemorrhage. J Jpn Soc Clin Surg 1989; 50:2594-2598. (in Japanese)
8. Kitamura M, Arai K, Miyashita K, and Iwasaki Y. Recurrence of gastric leiomyosarcoma in the abdominal cavity in the sixth postoperative year. Jpn J Gastroenterol Surg 1990; 23:2793-2797. (in Japanese)

9. Murakami N, Kawaura Y, Omura K, Munemoto Y, Harada $\mathrm{T}$ et al. A case report of a giant leiomyosarcoma of the stomach growing extragastric space. Syoukaki Geka 1991; 14:737-741. (in Japanese)

10. Shirai K, Nakao N, Miura K, Miura T, Hashimoto N et al. A huge gastric leiomyosarcoma diagnosed preoperatively through diagnostic imaging. Radiation Medicine 1991; 9:170-173.

11. Kobayashi N. A case report of a leiomyosarcoma of the stomach growing extragastric space which was difficult to make a differential diagnosis for the greater omental tumor. Nichidoku Ihou 1992; 37:390-391. (in Japanese)

12. Kishimoto H, Oka A, Sumikawa M, Hinohara $T$, Komatsu $\mathrm{K}$ et al. A case of gastric leiomyosarcoma with extragastric growth. Shimane Igaku 1992; 12:66-69. (in Japanese)

13. Iyoda A, Itoh A, Hirata $\mathrm{T}$, Degawa $\mathrm{H}$, Takagi A et al. A case of giant extragastric pedunculated leiomyosarcoma. J Jpn Soc Clin Surg 1993; 54:962-966. (in Japanese)

14. Sasaki M, Konishi T, Negishi S, Watanabe $H$, Nakashima $\mathrm{T}$ et al. A case of a extragastrically growing giant leiomyosarcoma of the stomach. Rinsho Geka (Clinical Surgery) 1993; 48:813-816. (in Japanese) 
15. Tachibana S, Matsuo A, Kajima T, Tsuchiya J, Hoshino $\mathrm{M}$ et al. A case of exogastric giant leiomyosarcoma with early gastric cancer. Jpn J Gastroenterol Surg 1994; 27:1795-1799. (in Japanese)

16. Tsurui M, Sanji T, Yamada M, Midorikawa M, Handa Y et al. A large gastric leiomyosarcoma with marked extragastric growth - a case report-. Gann no Rinsho (Jpn J Cancer Clin) 1994; 40:1120-1126. (in Japanese)

17. Kato M, Akimoto S, Hatta T, Kimoto K, Kohashi T et al. A case report of a giant extragastric pedunculated leiomyosarcoma of the stomach. Gann no Rinsho (Jpn J Cancer Clin) 1995; 41:311-315. (in Japanese)

18. Tatsuzawa Y, Nagamine H, Kawakami T, Yokoyama K, Tanaka $\mathrm{M}$ et al. A case of extragastrically growing giant leiomyosarcoma of the remnant stomach. Geka (Surgery) 1995; 57:355-358. (in Japanese)

19. Inoue K, Horimi T, Morita S, and Takasaki M. A case report: Giant gastric leiomyosarcoma, showing pedunculated extragastric development. Jpn J Gastroenterol 1995; 92:1942-1946. (in Japanese)

20. Miya A, Yasuda S, Morimoto O, Tsuji Y, Shiozaki K et al. A case of liver metastasis of gastric leiomyosarcoma successfully treated by transarterial hepatic chemo- embolization and intra hepato-arterial chemotherapy repeated with infusion-a-port. Jpn J Cancer Chemother 1997; 24:1878-1881. (in Japanese)

21. Kurita A, Takashima S, Kubo Y, Saeki T, Yokoyama N et al. Clinicopathological study of gastric leiomyosarcoma. Jpn J Gastroenterol Surg 1997; 30:2134-2139. (in Japanese)

22. Kitaoka H, Okabayashi K, Kinoshita T, Hirota E, Itahashi $\mathrm{M}$ et al. Prognostic factors and operative methods of the stomach with leiomyosarcoma. Gann no Rinsho (Jpn J Cancer Clin) 1983; 29:811-816. (in Japanese)

23. Grant CS, Kim CH, Farrugia G, Zinsmeister A, and Goellner JR. Gastric leiomyosarcoma. Arch Surg 1991; 126:985-990.

24. Crocker DW. Smooth muscle tumors of the stomach. Ann Surg 1969; 170:239-243.

25. Roles NC. Leiomyosarcoma of the stomach: an assessment. East Afr Med J 1966; 43:249-258.

26. Tsianos GB, Argiropoulos-Rakas CA, and Karkanias GG. Hemoperitoneum secondary to exogastric leiomyosarcoma: a case report. Hepato-Gastroenterology 1995; 42:885-887. 